\title{
ChemComm
}

\section{Supramolecular protection from the enzymatic tyrosine phosphorylation in a polypeptide $\dagger$}

Cite this: Chem. Commun., 2016, 52,8142

Received 9th May 2016

Accepted 28th May 2016

DOI: $10.1039 / c 6 c c 03875 a$

www.rsc.org/chemcomm

Here we report two new artificial pseudopeptidic cages that bind the EYE peptide epitope in pure water at physiological pH (as studied by fluorescence and NMR spectroscopies). The supramolecular complexation of the Tyr residues efficiently precludes their subsequent PTK-catalysed phosphorylation. Our results show a supramolecular modulation of the PTK activity by competitive substrate caging.

The molecular recognition of peptides and proteins is a hot topic in supramolecular chemistry, with important implications in chemical biology. ${ }^{1}$ However, the binding of peptides in pure water and at neutral $\mathrm{pH}$ is still a challenging issue, due to the competitive effect of water and the flexibility of the peptides in solution. ${ }^{2}$ Some examples using cucurbituril, ${ }^{3}$ cyclodextrin $^{4}$ or calixarene ${ }^{5}$ receptors have been reported mainly based on hydrophobic interactions that are favoured in pure water. Following our research with pseudopeptides, ${ }^{6}$ we have recently designed large pseudopeptidic cages as efficient receptors for dipeptides in organic or aqueous-organic solvents, showing a good selectivity for the Ac-EY-OH sequence. ${ }^{7}$ This selectivity is manifested in the differential binding of stereoisomers of the Ac-EY-OH dipeptide by CySer and CyThr cages (Fig. 1). ${ }^{8}$ Binding studies using several spectroscopic techniques with different dipeptides, combined with molecular mechanics calculations allowed defining a mode of binding. ${ }^{7,8}$ The corresponding host-guest complexes are stabilized by both polar (salt bridges and H-bonds) and non-polar ( $\pi-\pi$ stacking) interactions, where the encapsulation of the Tyr aromatic ring inside the cage cavity plays an important role. The Tyr residue in polypeptides is a biologically interesting target: for instance, the EYE sequence is a well-known substrate epitope of protein tyrosine kinases

\footnotetext{
${ }^{a}$ Department of Biological Chemistry and Molecular Modelling, IQAC-CSIC, Jordi Girona 18-26, 08034, Barcelona, Spain. E-mail: ignacio.alfonso@iqac.csic.es ${ }^{b}$ NMR Facility, IQAC-CSIC, Jordi Girona 18-26, 08034, Barcelona, Spain ${ }^{c}$ Department of Inorganic and Organic Chemistry, ESTCE Universitat Jaume I, Avd. Sos Baynat, s/n, 12004, Castellón, Spain.E-mail: luiss@uji.es

$\dagger$ Electronic supplementary information (ESI) available: Synthesis and characterization details, spectroscopic data, titration experiments and phosphorylation assays. See DOI: 10.1039/c6cc03875a
}

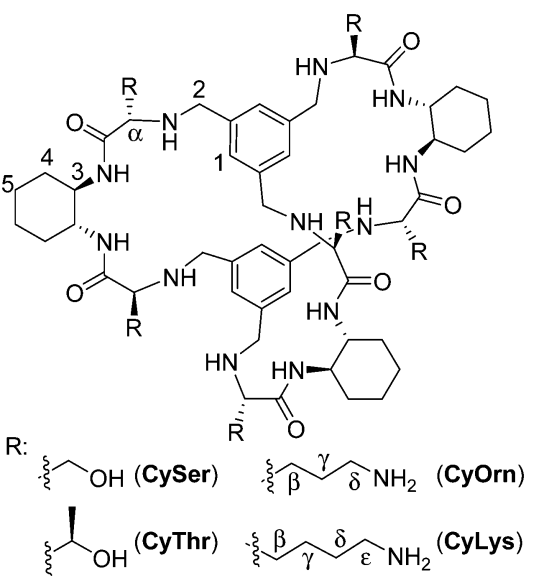

Fig. 1 Chemical structures of the pseudopeptidic cages, with the assumed labelling.

(PTKs), ${ }^{9}$ which catalyse the transfer of a phosphoryl group from ATP to the Tyr hydroxyl group. This phosphorylation is an important post-translational modification, being closely connected with cell regulation, signalling and growth. ${ }^{10}$ Thus, the abnormal function of PTKs is related to serious diseases, such as diabetes, ${ }^{11}$ cancer $^{12}$ and neurodegenerative diseases. ${ }^{13}$ Therefore, there is growing interest in the design and study of new molecules and mechanisms to modulate kinase activity. $\neq$

Inspired by the highly regulated action of PTK enzymes in nature, we envisioned that artificial cages with good affinity for the corresponding peptidic substrates would form stable supramolecular complexes, protecting the Tyr residues from the phosphorylation action of the enzyme (Fig. 2). Here we show that this supramolecular approach of PTK modulation can be performed using synthetic pseudopeptidic cages as competitive substrate binders.

To test our hypothesis, we used commercial poly(EY) as a model for the PTK substrate. ${ }^{9}$ Poly(EY) is a random $20-50 \mathrm{kDa}$ copolymer with a 4:1 Glu:Tyr molar ratio to maximize the occurrence of the EYE motif. Considering previous results, ${ }^{7,8}$ 


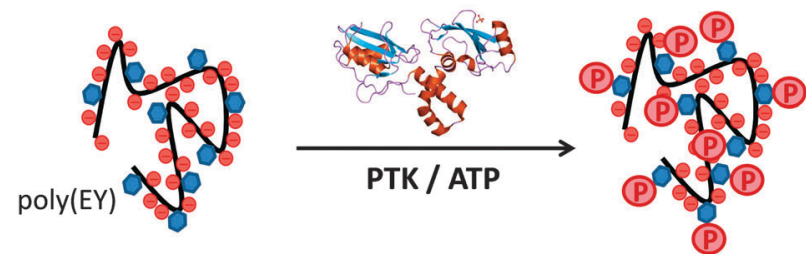

cagen $\downarrow \uparrow$
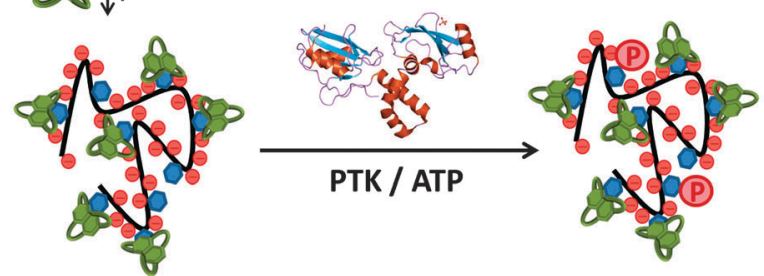

Fig. 2 Schematic representation of the proposed mechanism: the binding of the pseudopeptidic cage to the poly(EY) polypeptide protects the Tyr residues (blue hexagons in the cartoon) from the further phosphorylation mediated by PTK.

we designed two new hosts (CyOrn and CyLys, Fig. 1) with positively charged side chains at neutral $\mathrm{pH}$, to increase the interaction with the anionic poly(EY). These new cages were synthesized following a convenient modification of a reported procedure $^{14}$ (ESI $\left.\dagger\right)$. The mechanism schematically proposed in Fig. 2 is specially challenging from the supramolecular perspective since it requires a strong interaction between a nonnatural host (pseudopeptidic cages) and a highly solvated and flexible polypeptide in pure water at neutral $\mathrm{pH}$ (as shown by NMR and CD studies, see the ESI $\dagger$ ). Moreover, the PTK-poly(EY) contact can be considered a protein-protein interaction (PPI), which is difficult to disrupt with synthetic small molecules. ${ }^{15}$

First, we studied the binding between poly(EY) and the cages by fluorescence spectroscopy in buffered water (60 $\mathrm{mM}$ Tris buffer at $\mathrm{pH}$ 7.3). The titration of poly(EY) with CyOrn produced the quenching of the Tyr emission at $304 \mathrm{~nm}$, and the growth of an intense band at $385 \mathrm{~nm}$, with a clear isoemissive point at $358 \mathrm{~nm}$ (Fig. 3A). This lower energy band was assigned to the formation of a CyOrn-poly(EY) complex through the Tyr residue encapsulation. ${ }^{16}$ The non-linear fitting of this band to a $1: 1$ binding mode rendered a dissociation constant of $K_{\mathrm{d}}=920 \mu \mathrm{M}$ (Table 1, entry 1). The commercial poly(EY) is a poly-disperse molecule containing many EYE binding sites and, in principle, all of them could bind to the cage. Accordingly, for the quantitative measurements, we considered the concentration of the repeating units $\left(\mathrm{E}_{4} \mathrm{Y}\right)$ as the binding species, since each repeating unit contains a Tyr residue. Therefore, the $K_{\mathrm{d}}$ values here reported reflect the average affinity for each EYE binding site, assuming a 1:1 host-guest stoichiometry. As a confirmation of the proposed interaction, we studied the binding of CyOrn to the tripeptide Ac-EYE- $\mathrm{NH}_{2}$ by fluorescence spectroscopy, also rendering the appearance of the band at $385 \mathrm{~nm}$ and a similar $K_{\mathrm{d}}=1.17 \mathrm{mM}$ (entry 2 in Table 1 ). This result suggests that most of the Tyr residues in poly(EY) are accessible to the cage and that they behave as nearly independent binding sites.

The fluorescence titration of poly(EY) with CyLys produced different fluorescence emission spectra (Fig. 3B). A more complex
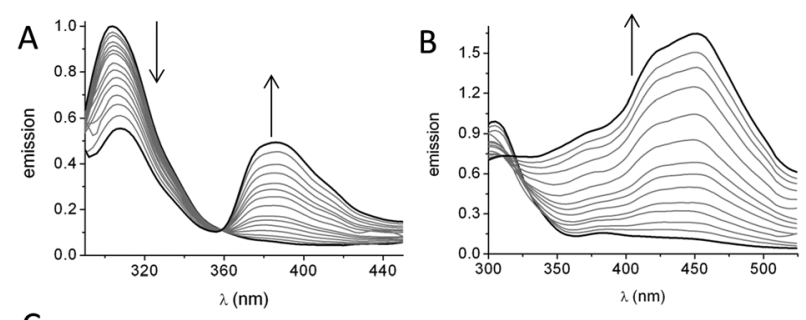

C
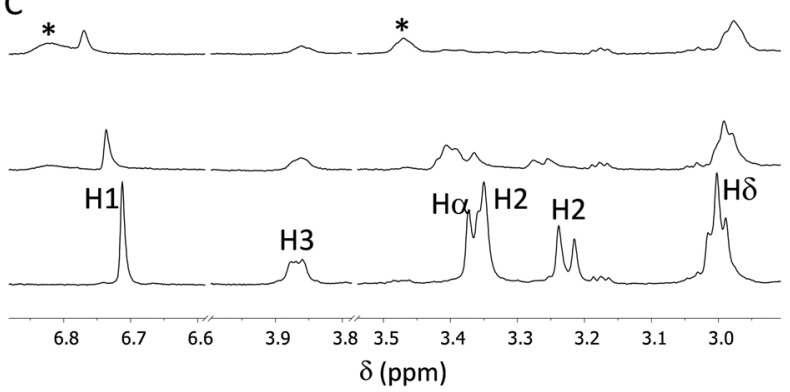

Fig. 3 Binding of cages to EYE peptides: normalized fluorescence spectra $\left(\lambda_{\text {exc }}=276 \mathrm{~nm}\right)$ of poly $(\mathrm{EY})\left(60 \mathrm{mM}\right.$ Tris buffer, $\mathrm{pH} 7.3$ at $\left.25^{\circ} \mathrm{C}\right)$ upon the addition of the cages: (A) $2 \times 10^{-4} \mathrm{M}$ poly(EY) titrated with $0-1.33 \times 10^{-3} \mathrm{M}$ CyOrn or (B) $4 \times 10^{-5} \mathrm{M}$ poly(EY) titrated with $0-3.3 \times 10^{-4} \mathrm{M}$ CyLys. (C) Partial $T_{1 p}$-filtered ${ }^{1} \mathrm{H}$ NMR spectra of CyOrn (0.4 mM in $\mathrm{D}_{2} \mathrm{O}, 75 \mathrm{mM}$ Tris buffer, pD 7.4 at $25^{\circ} \mathrm{C}$ ) alone (lower trace) and with increasing amounts of poly(EY) (upper traces, $0.45 \mathrm{mM}$ and $0.75 \mathrm{mM}$ poly(EY), respectively). Signals marked with $\left(^{*}\right)$ correspond to the poly(EY). In all the cases the concentration of poly(EY) refers to the concentration of the repeating unit, $E_{4} Y$.

Table 1 Dissociation constants $\left(K_{\mathrm{d}}, \mu \mathrm{M}\right)$ for the interaction between the cages and different peptides in buffered water at $25^{\circ} \mathrm{C}$

\begin{tabular}{|c|c|c|c|c|}
\hline Entry & Cage & Peptide & $\mathrm{pH}$ & $K_{\mathrm{d}}^{a}(\mu \mathrm{M})$ \\
\hline 1 & CyOrn & Poly(EY) & 7.3 & $920^{b}$ \\
\hline 2 & CyOrn & $\mathrm{Ac}-\mathrm{EYE}-\mathrm{NH}_{2}$ & 7.3 & $1170^{b}$ \\
\hline 3 & CyLys & Poly(EY) & 7.3 & $450^{b}$ \\
\hline 4 & CyLys & Ac-EYE-NH ${ }_{2}$ & 7.3 & $570^{b}$ \\
\hline 5 & CyLys & Poly(EY) & 5.3 & $140^{b}$ \\
\hline 6 & CyLys & Poly(EY) & 8.7 & $440^{b}$ \\
\hline 7 & CyOrn & Poly(EY) & $7.4(\mathrm{pD})$ & $403^{c}$ \\
\hline 8 & CyLys & Poly(EY) & $7.4(\mathrm{pD})$ & $395^{c}$ \\
\hline 9 & CyLys & Poly(EY) & $7.3(\mathrm{NaCl})$ & $342^{b}$ \\
\hline 10 & CyLys & Ac-YEEI-NH ${ }_{2}$ & 7.3 & $526^{b}$ \\
\hline 11 & CyLys & Ac-EEEIYEEFD-NH ${ }_{2}$ & 7.3 & $500^{b}$ \\
\hline
\end{tabular}

${ }^{a}$ Estimated statistical errors $<15 \% .{ }^{b}$ Measured by fluorescence titration of the Tyr containing peptide upon addition of the cage. ${ }^{c}$ Measured by NMR titration of the cage by addition of the peptide.

band at longer wavelength was observed upon the addition of the cage. Thus, the emission spectra showed several maxima $(375 \mathrm{~nm}$, $420 \mathrm{~nm}$ and $450 \mathrm{~nm}$ ), probably corresponding to the co-existence of different complexes. The non-linear fitting of the fluorescence data rendered a slightly stronger interaction (Table 1, entry 3), which was also confirmed by performing the titration experiments with a minimal expression of the binding epitope Ac-EYE- $\mathrm{NH}_{2}$ (Table 1, entry 4). The different shape of the spectra with CyLys could be due to a different protonation degree of the complexes, since CyLys is more basic than CyOrn (see the ESI $\dagger$ ). This hypothesis was confirmed by performing additional titration experiments at different $\mathrm{pH}$ (Table 1, entries 5 and 6), which 
showed similar binding constants but different shapes of the emission spectra (Fig. S33 in the ESI $\dagger$ ). Thus, the maximum at $450 \mathrm{~nm}$ is more intense at lower $\mathrm{pH}$ while the band at $375 \mathrm{~nm}$ increases at higher $\mathrm{pH}$, suggesting that the differences in the titration with CyOrn or CyLys must be due to a higher protonation degree of the complex formed with CyLys.

Spin-lock filtered NMR experiments ${ }^{17}$ were also employed for studying the binding process in solution. This NMR technique uses the spin-lattice relaxation time in the rotating frame $\left(T_{1 \rho}\right)$ as the binding probe thanks to its dependence on the correlation time. Thus, the relaxation of the cage is highly enhanced upon binding to the poly(EY), leading to a decrease in the intensity of the NMR signals in the $T_{1 \rho}$ filtered ${ }^{1} \mathrm{H}$ NMR experiment. Accordingly, titration of CyOrn with poly(EY) in $\mathrm{D}_{2} \mathrm{O}(75 \mathrm{mM}$ deuterated Tris, $\mathrm{pD}$ 7.4) induced a decrease in the intensity of many ${ }^{1} \mathrm{H}$ NMR signals (Fig. 3C) implying an efficient interaction in solution. Moreover, some signals from the cage also shifted upon binding, mainly those corresponding to the aromatic tripodal ring (H1) and the methylene close to the primary amine of the side chains $(\mathrm{H} \delta)$. The non-linear fitting of the variation of the chemical shift of the $\mathrm{H} 1$ singlet rendered a $K_{\mathrm{d}}=403 \mu \mathrm{M}$ (Table 1 , entry 7), which is within the same order of the value obtained by fluorescence spectroscopy. The experiments performed with CyLys rendered parallel results and a comparable binding constant (Table 1, entry 8 and ESI $\dagger$ ). The 2D-NOESY experiment of a mixture of CyLys and poly(EY) (500 MHz, deuterated Tris buffer in $\mathrm{D}_{2} \mathrm{O}$ at pD 7.4, Fig. S49 in the ESI $\dagger$ ) showed an intermolecular cross-peak between $\mathrm{H} 1$ of the cage and $\mathrm{H} \varepsilon$ of the Tyr residues of the peptide. This NOE further supported the proposed binding in solution. The CyLys cage was also able to bind to poly(EY) in the presence of $150 \mathrm{mM} \mathrm{NaCl}$ (Table 1, entry 9), a more challenging solvent for the interaction.

Considering that the prepared cages showed efficient binding of the EYE peptide sequence in pure water at neutral $\mathrm{pH}$, we envisioned the possibility of the cages to protect the peptides from the action of the PTK enzyme. To that, we used an in vitro commercial assay for the evaluation of the effect of the cages on the phosphorylation reaction (assay description in the ESI $\dagger$ ). ${ }^{18}$ We performed the experiments in the presence of the cages at different concentrations and the results were transformed into the remaining percent of kinase activity by comparison with the control experiment in the absence of cage (Fig. 4). Also CySer and CyThr (Fig. 1) were included as controls, since both showed very weak binding to the poly(EY) substrate in buffered water (by NMR and fluorescence spectroscopy, see the ESI $\dagger$ ). All the cages were able to partially protect the substrates from the tyrosine kinase phosphorylation, showing differences depending on the cage structure and its concentration. The cages derived from Ser and Thr displayed a modest protection, requiring a high concentration $(9 \mathrm{mM})$ to yield an $\sim 30 \%$ decrease of phosphorylation. Since they showed practically no effect at $1 \mathrm{mM}$, lower concentrations were not tested.

This low activity clearly correlates with their weaker binding to the EYE motif. However, CyOrn and CyLys displayed interesting competition with the PTK in the sub-millimolar range. At concentration values (0.26-1.10 $\mathrm{mM})$ close to the corresponding

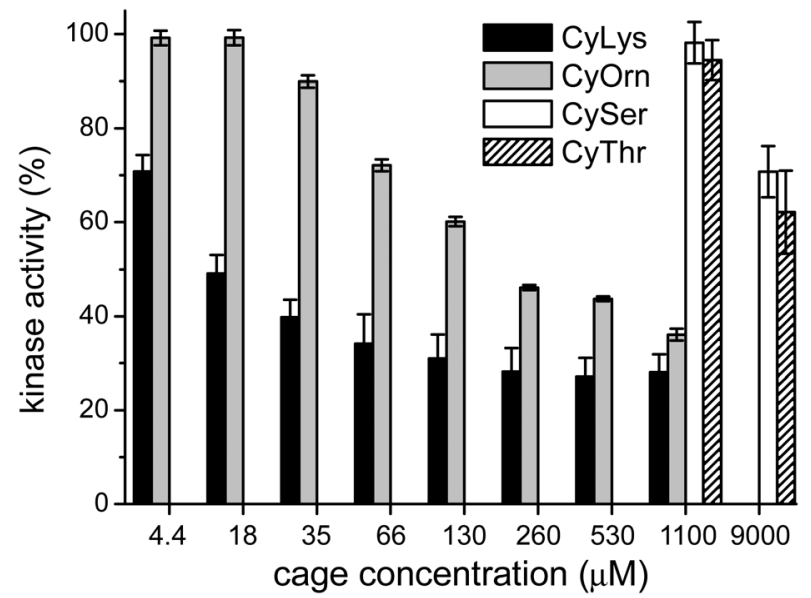

Fig. 4 In vitro enzymatic phosphorylation assays: PTK catalyzed phosphorylation of the poly(EY) substrate in the presence of different concentrations of the pseudopeptidic cages. The values show the average of two independent experiments, each one in three replicated measurements, with error bars showing the standard deviations.

$K_{\mathrm{d}}$ for the EYE-cage binding, the CyOrn host showed a 50-60\% decrease in the phosphorylation, which can be directly ascribed to the cage-peptide recognition. Quite remarkably, a higher activity was observed for CyLys, with $\sim 70 \%$ protection from the kinase action in the $0.26-1.10 \mathrm{mM}$ concentration range. These differences are more evident at lower concentrations of the cages: for instance, at $18 \mu \mathrm{M}$ CyLys $\sim 50 \%$ protection was produced while CyOrn was practically inactive ( $\sim 100 \%$ of the remaining kinase activity, Fig. 4$)$. The longer side chains of the Lys derivative lead to a more positively charged and more hydrophobic cage, which could produce a multivalent effect in the binding process, especially for this assay where the polypeptide substrate is anchored to a surface with possible clustering of the supramolecular complexes. Thus, the trends clearly reflect the validity of our proposal, since the cages with a higher affinity for the EYE motif showed a more efficient protection from the PTK-mediated phosphorylation reaction.

The modulation of the biochemical machinery with synthetic molecules has become a common procedure to study biological processes and, ideally, to design chemical tools for the treatment of diseases. In these cases, ad hoc designed synthetic molecules are prepared to bind large biomolecular systems (usually proteins). Within this rational, the inhibition of enzymatic activity has been normally faced by preparing chemicals able to bind the catalytic site of the enzymes. ${ }^{12 a}$ Here we demonstrated a complementary approach based on supramolecular chemistry. Thus, we have used the synthetic molecule to bind the substrate of the enzyme instead of the enzyme itself. This approach has been previously used to inhibit proteases $^{3 c, f}$ and a demethylase $\mathrm{e}^{5 e}$ but, to the best of our knowledge, it has never been used to modulate a kinase activity. This host-guest approximation shows the advantage of allowing a better implementation of substrate selectivity, in case the same enzyme is implicated in the modification of different substrates (as it is common for kinases). Despite the moderate potency of our cages for a formal PTK inhibition, the supramolecular 
mechanism of action targeting the substrate of the enzyme will open a new way for kinase activity modulation. The selectivity needed for improving this supramolecular kinase modulation can be tailored by structural modifications in the pseudopeptidic cages, thus possibly targeting known phosphorylation consensus sequences with specific characteristics. ${ }^{19}$ Thus, for instance, CyLys also recognized two Tyr-containing peptides (entries 10 and 11 in Table 1) that are target sequences of biologically relevant kinases, ${ }^{20}$ foreseeing the potential real applications of these cages.

In conclusion, the new pseudopeptidic cages described here efficiently recognize the EYE peptide sequence in buffered water, as shown by fluorescence and NMR spectroscopies. The binding occurs both with the isolated tripeptide and when the EYE motif forms part of a longer polypeptide chain as a model of a biomacromolecule. This supramolecular interaction efficiently protects the Tyr side chain from the enzymatic phosphorylation, as shown by in vitro kinase assays. Besides, the decrease in the phosphorylation degree can be roughly correlated with the cage-EYE sequence affinity. We believe that our results have wide implications, since they open a way to use supramolecular systems to modulate biochemical processes by substrate recognition, thus possibly hiding the substrates from their natural receptor or enzyme. A further generalization of this concept is under study in our group.

This work was supported by MINECO/FEDER (CTQ201238543-C03, CTQ2015-68429-R and CTQ2015-70117-R projects) and Generalitat de Catalunya (AGAUR, 2014 SGR 231).

\section{Notes and references}

$\$$ As an illustration of the current interest on kinases, see the American Chemical Society joined special issue on this topic at http://pubs.acs. org/page/vi/2014/kinases.html.

1 (a) W. C. Still, Acc. Chem. Res., 1996, 29, 155-163; (b) M. W. Peczuh and A. D. Hamilton, Chem. Rev., 2000, 100, 2479-2494; (c) S. Tashiro, M. Tominaga, M. Kawano, B. Therrien, T. Ozeki and M. Fujita, J. Am. Chem. Soc., 2005, 127, 4546-4547; (d) M. Wehner, D. Janssen, G. Schäfer and T. Schrader, Eur. J. Org. Chem., 2006, 138-153; (e) J. E. Beaver and M. L. Waters, ACS Chem. Biol., 2016, 11, 643-653.

2 (a) C. Schmuck and L. Geiger, J. Am. Chem. Soc., 2004, 126, 8898-8899; (b) C. Schmuck, Coord. Chem. Rev., 2006, 250, 3053-3067; (c) F. Biedermann, U. Rauwald, M. Cziferszky, K. A. Williams, L. D. Gann, B. Y. Guo, A. R. Urbach, C. W. Bielawski and O. A. Scherman, Chem. - Eur. J., 2010, 16, 13716-13722; (d) T. Gersthagen, J. Hofmann, F.-G. Klärner, C. Schmuck and T. Schrader, Eur. J. Org. Chem., 2013, 1080-1092; (e) S. Yapar, M. Oikonomou, A. H. Velders and S. Kubik, Chem. Commun., 2015, 51, 14247-14250.

3 (a) L. M. Heitmann, A. B. Taylor, P. J. Hart and A. R. Urbach, J. Am. Chem. Soc., 2006, 128, 12574-12581; (b) M. V. Rekharsky,
H. Yamamura, C. Inoue, M. Kawai, I. Osaka, R. Arakawa, K. Shiba, A. Sato, Y. H. Ko, N. Selvapalam, K. Kim and Y. Inoue, J. Am. Chem. Soc., 2006, 128, 14871-14880; (c) A. Hennig, G. Ghale and W. M. Nau, Chem. Commun., 2007, 1614-1616; (d) M. V. Rekharsky, H. Yamamura, Y. H. Ko, N. Selvapalam, K. Kim and Y. Inoue, Chem. Commun., 2008, 2236-2238; (e) J. M. Chinai, A. B. Taylor, L. M. Ryno, N. D. Hargreaves, C. A. Morris, P. J. Hart and A. R. Urbach, J. Am. Chem. Soc., 2011, 133, 8810-8813; $(f)$ L. A. Logsdon and A. R. Urbach, $J$. Am. Chem. Soc., 2013, 135, 11414-11416; $(g)$ L. C. Smith, D. G. Leach, B. E. Blaylock, O. A. Ali and A. R. Urbach, J. Am. Chem. Soc., 2015, 137, 3663-3669; (h) C. Parente Carvalho, A. Norouzy, V. Ribeiro, W. M. Nau and U. Pischel, Org. Biomol. Chem., 2015, 13, 2866-2869.

4 (a) H. Yamamura, M. V. Rekharsky, Y. Ishihara, M. Kawai and Y. Inoue, J. Am. Chem. Soc., 2004, 126, 14224-14233; (b) Y. Liu, Y.-W. Yang, Y. Chen and F. Ding, Bioorg. Med. Chem., 2005, 13, 963-971; $(c)$ H. S. Christensen, B. W. Sigurskjold, T. G. Frihed, L. G. Marinescu, C. M. Pedersen and M. Bols, Eur. J. Org. Chem., 2011, 5279-5290.

5 (a) F. Sansone, L. Baldini, A. Casnati and R. Ungaro, New J. Chem., 2010，34，2715-2728; (b) A. D. Stancu, H.-J. Buschmann and L. Mutihac, J. Inclusion Phenom. Macrocyclic Chem., 2012, 75, 1-10; (c) R. E. McGovern, H. Fernandes, A. R. Khan, N. P. Power and P. B. Crowley, Nat. Chem., 2012, 4, 527-533; (d) R. E. McGovern, A. A. McCarthy and P. B. Crowley, Chem. Commun., 2014, 50, 10412-10415; (e) H. Peacock, C. C. Thinnes, A. Kawamura and A. D. Hamilton, Supramol. Chem., 2016, 28, 575-581.

6 (a) S. V. Luis and I. Alfonso, Acc. Chem. Res., 2014, 47, 112-124; (b) I. Alfonso, Chem. Commun., 2016, 52, 239-250.

7 E. Faggi, A. Moure, M. Bolte, C. Vicent, S. V. Luis and I. Alfonso, J. Org. Chem., 2014, 79, 4590-4601.

8 E. Faggi, C. Vicent, S. V. Luis and I. Alfonso, Org. Biomol. Chem., 2015, 13, 11721-11731.

9 D. M. Williams, D. Wang and P. A. Cole, J. Biol. Chem., 2000, 275, 38127-38130.

10 M. D. Haskell, J. K. Slack, J. T. Parsons and S. J. Parsons, Chem. Rev., 2001, 101, 2425-2440.

11 A. Fountas, L.-N. Diamantopoulos and A. Tsatsoulis, Trends Endocrinol. Metab., 2015, 26, 643-656.

12 (a) A. J. Bridges, Chem. Rev., 2001, 101, 2541-2572; (b) J. B. Casaletto and A. I. McClatchey, Nat. Rev. Cancer, 2012, 12, 387-400.

13 (a) J. Ma, T. Jiang, L. Tan and J.-T. Yu, Mol. Neurobiol., 2014, 51, 820-826; (b) R. Abbassi, T. G. Johns, M. Kassiou and L. Munoz, Pharmacol. Ther., 2015, 151, 87-98; (c) A. F. T. Arnsten, Nat. Neurosci., 2015, 18, 1376-1385.

14 A. Moure, S. V. Luis and I. Alfonso, Chem. - Eur. J., 2012, 18, 5496-5500.

15 L.-G. Milroy, T. N. Grossmann, S. Hennig, L. Brunsveld and C. Ottmann, Chem. Rev., 2014, 114, 4695-4748.

16 M. Shanmugam, D. Ramesh, V. Nagalakshmi, R. Kavitha, R. Rajamohan and T. Stalin, Spectrochim. Acta, Part A, 2008, 71, 125-132.

17 P. Śledź, C. Abell and A. Ciulli, NMR of Biomolecules, Wiley-VCH Verlag GmbH \& Co. KGaA, 2012, pp. 264-280.

18 Y. Jia, X.-j. Gu, A. Brinker and M. Warmuth, Expert Opin. Drug Discovery, 2008, 3, 959-978.

19 S. Lee, X. Lin, N. H. Nam, K. Parang and G. Sun, Proc. Natl. Acad. Sci. U. S. A., 2003, 100, 14707-14712.

20 R. Amanchy, B. Periaswamy, S. Mathivanan, R. Reddy, S. G. Tattikota and A. Pandey, Nat. Biotechnol., 2007, 25, 285-286. 